\title{
Climb Every Mountain! Conquering Queensland's 'cliff' Year through Learning Innovation
}

\author{
Jim Nyland ${ }^{1}$, David Davies ${ }^{2}$, Emer Clarke $^{3}$ \\ Australian Catholic University, Australia \\ University of Derby ${ }^{2}, U K$ \\ Research Associate ${ }^{3}, U K$
}

\begin{abstract}
This research project is aimed to support the strategic vision and development of the Australian Catholic University (ACU) Brisbane Campus, focusing on its student voice in determining future needs and perspectives for the campus in preparation for the so called 'cliff year' in 2019, that will see $40 \%$ less students graduate Year 12 in Queensland due to the introduction of a full time Preparatory program in 2007 and commencement of a half cohort of 'Prep' to align with the shift in the compulsory school starting age from 2008. The project's findings suggest that the emphasis given to professional knowledge and practice can be underpinned by recognition of a number of factors which impact on current learning such as the importance of personal viability and selfunderstanding where both survival and success mean individuals must promote their skills and capacities, establish a balanced life where personal needs and social awareness are reconciled, and where responsibility for learning and self-development are recognised, not least in the world of digital communication.
\end{abstract}

\section{Introduction}

In Queensland, the hills are alive to the sound of the student voice as universities look to the impending 'cliff' year on the horizon and consider how best to chart a course for their organisations to avoid troubled waters and rocky shores. 2019 will see $40 \%$ less students graduate Year 12 in Queensland due to the introduction of a full time Preparatory program in 2007 and commencement of a half cohort of 'Prep' to align with the shift in the compulsory school starting age from 2008. The vision for higher education in Queensland seems increasingly focused on emergent innovations around trimesters, pathways and new products and programs as well as fresh ideas about how to widen access and participation for non-school leavers, expand online delivery and cleverly position 'brand University' within an acutely competitive environment. It seems timely to ask students (as well as staff) what attracts them to our University in order to understand how choices and experiences can help shape the future of learning on our university campus. ACU Brisbane has a history of listening and responding effectively to the student voice - the Brisbane campus has experienced annual double digit growth over the last five years, resulting in a headcount of 5400 students today and planned future growth will see this figure increase to 8000 students when Queensland reaches the edge of its cliff. Students continue to choose to come to our campus for a number of reasons and some of these have been captured in the recent study 'Real learning in the changing university'. This research project involved 25 in-depth interviews with students from 4 faculties at ACU Brisbane. 17 of the students were female, 8 were male, 12 were under 25 years old and 13 were over 25 . Two interviewers assembled the data collected from the student volunteers, which covered not only actual experiences of learning and studying at $\mathrm{ACU}$ Brisbane but also their feelings about a range of issues which are impacting on their studies and on their futures.

\section{Background}

\section{"Students are the single most important resource of our universities"}

More than two decades have passed since this statement startled the world of higher education [10]. Since then universities' perceptions of their students have in many cases been successfully incorporated within more responsive underlying university cultures. Nevertheless, teaching and learning strategies have remained somewhat impervious to some major changes which have occurred on a global scale.

The project aimed to support and develop the strategic vision and operations of ACU as it seeks to deepen its concern for students' overall experience. In particular it was intended to focus on the Brisbane Campus and the potential impact of the student voice 
in determining future needs and perspectives for the University.

The University's prime concerns were to implement the transition from growth to 'excellence', to consolidate its share of the expanded, demand driven student market, to develop its academic strengths and specialisms and to achieve eminence in chosen areas of research. The focus of this particular research is the critical issues which shape the curriculum and impact on the student experience, their learning and choices.

This report is part of a continuing study to inform and critically analyse developments in universities world-wide which have impacted on students' choices of ways of learning and of academic subjects. It presents aspects of a research project being developed at the ACU Brisbane campus by a team with Australian national and international experience. The context for the project lies in the impact of globalisation on higher education (HE) institutions worldwide. Key aspects include the changing nature of student subject choices, the evolution of web-based and internet focused learning, the impact of digitalisation and the increasing need for a more 'real' and 'relevant' HE curriculum.

The 'condensation' of the experience of students at an Australian campus within a managed, mixed mode research project enables student views to be articulated. Student narratives and 'felt experience' have been given credence within the research strategy. The objectives of the project included giving a voice to students and creating possibilities for defining 'real learning'.

The research data and associated papers attempt to understand contemporary learning expectations and preferences of students within a set of 'frameworks' which we believe will continue to illuminate critical issues and concerns including:

- the impact of digitalisation and new literacies

- the failure of some social market models to engage with mass learning needs

- the need for HE institutional renewal

- the possibilities for institutional renewal in the context of ACU's Brisbane campus

- the re-affirmation that learning for a social purpose is a continuing motive for modern universities

- the need for what we have termed 'real' learning in the changing university.

\section{Context}

ACU, Brisbane is one of the fastest growing University campuses in Australia in recent years, and for a period during this time, has been the fastest. At a time when Australia has sought to transform itself into a learning society, Higher Education has come to be regarded as a fundamental entitlement for a mass client group rather than as a select privilege for a few. ACU Brisbane has been a major beneficiary of this demand driven system which has seen more Australians go to university than at any other time in their history with over 1 million individuals now attending university campuses across the nation. The Australian Catholic University is one of the world's leading Catholic universities with over 32000 students spread across seven campuses in four States and one Territory. Ten years ago ACU Brisbane was seen as a marginal player in the Queensland $\mathrm{HE}$ sector and was widely regarded as the campus least likely to succeed amongst its 'sister' campuses owned by the nine universities operating in Queensland. Today it is the stand-out campus amongst those it was previously twinned with and whilst many university sites across the State have either stalled, gone backwards or closed, ACU Brisbane has more than doubled its student numbers over the last five years and has established major research Institutes in the heart of Brisbane in the areas of Health and Education. By way of example, the Learning Sciences Institute, headquartered at ACU Brisbane, was recently awarded more than twice as many premier research Grants (Discovery Grants) in the field of Education of any University in Australia. The momentum that is driving ACU Brisbane has seen it become a University of choice for staff, students and partners who are struck by one of Australia's most innovative university campuses that offers a critical curriculum relevant to people's lives, re-states and reforms the access and excellence agenda in new times, and is a motor for critique, rejuvenation and renewal for all, not just the few. ACU Brisbane continues to harvest the benefits of creating the space, imagination and organisation to make a modern university with traditional values work in the interests of broad masses of people who see $\mathrm{HE}$ as their way to a decent and secure future.

ACU Brisbane's value proposition and Catholic identity recognises the essential interdependence of social life. Values and identities are located in work, in labour, in community life, in social activity and in reflective self-consciousness which have significance way beyond any profit to be made from them. It is vital that we seek the content of these values so that we can organise and educate around them. The rebalancing of economy and society has profound implications for the role and functions of universities, not least for the way we shape learning and qualifications for an uncertain and disruptive future. Going to university then is no longer a privilege for the elite few, rather it is an open door 
for all those who richly deserve the opportunity to enter higher education at a time in our history when most worthwhile jobs created require a university qualification, and most graduate incomes are twice that of non-graduates. That said, this research project highlights the fact that completion of an ACU Brisbane Degree offers students something more than a brighter career plan - its point of difference is a distinctively strong values base which draws upon the great Catholic intellectual tradition and shapes the impact individuals have on their chosen profession and society more generally.

This approach to reshaping universities with a focus on real and relevant learning moves the idea of engagement from traditional outreach activities to the very core of their research and teaching, enabling universities to become sites for the production of knowledge in the context of application. In seeking to become producers of innovative forms of curriculum and developers of socially robust knowledge, this report highlights the challenge for universities to continue to move away from being on 'transmit' mode - changing paternalistic notions of 'knowledge transfer' to communities - to a more collaborative paradigm of 'knowledge creation' with communities. Conceptually, the challenge put forward here is for universities to rapidly expand their social contracts with work and society that allows active citizenship through workplace learning to flourish. University leaders have to think of new ways to devise and implement a range of innovative strategies concerned with innovation in curriculum content, learning methodologies, education skills and the planning and management of learning. Above all, these developments chart the recognition of the fact that there is now in existence a "dynamic curriculum". This curriculum embraces the open paradigm; its pedagogy is similarly open to student experience and it insists that knowledge is crafted from learning experiences, wherever and whenever these occur. This research project highlights the fact that the role of work and the need for lifelong and work-related learning has changed radically for many people - thus, the notion of a dynamic curriculum appears as an idea whose time has come!

A number of factors have shaped recent perceptions of what could be done at ACU Brisbane to support the successful implementation of the new strategy. These include:

- the specific growth and development of curriculum areas and professional learning in the local and regional economies

- the need to know and research student expectations and behaviour in relation to choices of subjects and careers offered at ACU Brisbane
- campus and off-campus growth and the increased footfall across Queensland

- evidence of student choice and the student voice from the wider university sector

- the significance ACU Brisbane has for the wider Australian debate on the future of university education.

The crucial themes of the research involve engagement with 5 sets of issues and challenges and are set out below:

a. Global developments- which see the hollowing out of traditional economies and communities, the creation of mass migration, de-skilling of traditional labour markets, a rapid pace of change, a vulnerable ecology and de-stabilised communities.

b. University life as an adaptive response to the failures of some social market models-which has involved the growth of mass higher education, the marketisation of learning and growth of demand-led provision, the emergence of mass, on-line learning (Moocs for example) and a sense of permanent re-structuring of universities and their staff.

c. Work as a key site of learning -and of work itself as a 'principle' of learning and opportunity.

d. The impact of digital and new literacies-which involve new skills of personal performance, multi-tasking across different media, transmedia navigations, distributed cognition and the role of digital networking- on university life, study and achievement. Both opportunities and dangers are at hand in this development.

e. The possible future for universities- which would include the need for a curriculum more relevant to people's lives, a revised approach to access and widening participation and a view of universities as a motor for economic renewal and social rejuvenation.

The centrality of the student experience and aspirations was thought to be of crucial importance to the research project. In the final analysis, a curriculum is 'lived' through learning and teaching and it becomes 'real' only through the experience of the students. The project set out to capture some of this experience and to use it to better understand an ever-changing world of learning and scholarship.

\section{Project overview}

\subsection{The scope of the project}

- 4 Faculties at ACU Brisbane were involved in a practical research activity designed to answer the key research questions suggested below at 4.1 
- 25 in-depth student interviews were conducted involving students from across all the faculties

- the research approach was an amalgam of quantitative and qualitative methods; Mayring's model of inductive category development [14], [15] was adopted which allowed the empirical research data to be modelled through critical and analytical concepts

- the project was intended to yield outcomes in the form of critical and informative data and insights covering: the University's developing curricular needs; University and community links; partnerships with professional workplaces; and the needs of students focussed on self-reliance, social awareness and enhancement of personal viability.

\subsection{Schedule and time-table}

August-December 2014 - the research proposal was considered by ACU Brisbane

November 2014 - London- International Conference (LICE) presentation of paper and workshop on the 'Real Learning in the Changing University' project

December 2014- Publication of paper as an 'Extended Abstract' in LICE proceedings

January - March 2015 - detailed methodology and research framework developed

March 2015 - interview and data collection at ACU Brisbane; discussions with staff on initial scoping, methodology and research categories

April - June 2015 - transcription of interview data June - August 2015 - writing up of research findings and analysis.

\subsection{Ethics}

The research project implemented the ethics policies and procedures of ACU.

The students received an ethics form and were required to sign this as their consent to taking part in the project. Confidentiality and security of data was safeguarded and the academic authority of the University was considered to be paramount.

\subsection{Outputs from the research in 2015}

- London - Real learning in the changing university (1). London International Conference Proceedings on Education

- United Kingdom - Old wine in new wineskins. International Journal of Technology and Inclusive Education

- Brisbane - Real learning in the changing university (2). Internal Research Report for ACU Brisbane.
- Sydney - Real knowledge: towards a new university curriculum. Engagement Australia Conference Proceedings

- Australia - Real and relevant learning in the changing university - towards a new university curriculum. The Australasian Journal of University-Community Engagement.

- Dublin - Real learning in the changing university (3). World Congress on Education.

\section{Methods}

\subsection{Research design}

The project was organised primarily around a qualitative research method which relies on an adapted version of Mayring's inductive category formation model. Essentially, this involves a mixed approach to collecting and handling data. A framework of concepts and ideas drove the initial thoughts the team had about learning and social contexts, such as for example, the impact of 'globalisation', the evolution of 'mass- higher education' and the on-set of 'digital multi-tasking'. A tentative theoretical position was reached which allowed research questions to be formed and tested. A key words in context (KWIC) approach was adopted so as to allow events and experiences and the conditions under which they occurred to be described. Limited but valid generalisations were therefore wanted. The project set out to make clear some of the rules and relationships between variables in a real and existing environment- ACU at Brisbane, as it moves into its intended future in an era of uncertainty, challenge and opportunity for its students.

\subsection{Key research issues and questions}

The research issues and questions which informed the design of the methodology of the project were as follows:

- What does the student voice say about the key themes and issues outlined here especially at section 2.2 above?

- How can ACU Brisbane support the student experience in the light of the questions facing existing and future graduates?

- Can we identify and define a clearly relevant core and 'real' curriculum which will help students engage with the challenges of change?

- How does the digitalisation of learning and communication impact on our students on their learning and life experience and on their futures? 
- How can campus buildings at ACU Brisbane contribute to the emerging agenda of real and relevant learning?

- Do we identify the real qualities and potential of all of our students and reward personal viability, self-reliance and entrepreneurialism at the grass roots?

\subsection{Interview process}

The key concern of the research was to grasp the lived reality of a situation involving HE students' experiences, perceptions and feelings. The project termed this 'capturing the student voice' and assumed that social reality is created in interaction and through interpretation explored in qualitative research. A semi-structured interview allowed the respondents to communicate underlying attitudes, values and beliefs and to express some of the feelings of an individual.

Following theoretical considerations a set of central descriptive variables was defined for the project, including:

- volunteer students from vocational/professional study areas (4 faculties at ACU Brisbane represented)

- participation characteristics (demographics-age, gender)

- second and third year (advanced) undergraduates where possible

- age and gender neutrality of respondents

- learning experiences involved with digital technologies

- the Catholic ethos of the University

- feelings students had about the campus and their environment.

The research involved semi-structured in-depth interviews with 25 students. The sample size was restricted so that relatively intensive data collection was possible. Selection and notifications were carried out within the ethical procedures of the ACU Ethics Committee. Two researchers conducted interviews with 25 student volunteers over four days in March 2015 at the Brisbane Campus of ACU. Twenty-three of the interviews were face-to-face and there were two telephone interviews with students who were unable to attend campus. Nineteen of the face-to-face interviews were recorded and wordprocessed transcripts were subsequently available to the researchers. Handwritten notes were taken by both interviewers during the interviews. The semistructured open-ended interview allowed interviewees to discourse on some 18 questions (see Annex 2: Interview questions). The table below describes the gender and age of the students who were interviewed.
Table 1. Gender and age breakdown of interviewees

\begin{tabular}{|c|c|c|c|c|c|}
\hline $\begin{array}{l}\text { Number of } \\
\text { interviewees }\end{array}$ & \multicolumn{2}{|c|}{ Gender } & \multicolumn{3}{c|}{ Age } \\
\hline & Female & Male & $\begin{array}{c}18- \\
21 \mathrm{yrs}\end{array}$ & $\begin{array}{c}22- \\
25 y r s\end{array}$ & $\begin{array}{c}\text { Over } \\
25 \\
\text { yrs }\end{array}$ \\
\hline $\mathbf{2 5}$ & 17 & 8 & 7 & 5 & 13 \\
\hline
\end{tabular}

\subsection{Procedures}

The research approach was an amalgam of quantitative and qualitative methods. Mayring's model of inductive category development was adopted which allowed the empirical research data to be modelled through critical and analytical concepts. The method used is a controlled process that respects theory and standardised procedures for enquiry and analysis. It is a search for generalisations about relationships between categories of data. The data is paraphrased by selection and grouped and the context is taken into account to improve understanding of the text. In this study inductive expressions of feelings and experiences about current and future learning are understood as coding units (category definitions). Feelings include emotional responses to questions, whilst experiences refer to description and narratives, which have taken place. The unit of analysis is each separate, single transcript of an interview.

Two main procedures using qualitative analysis were followed. In the first procedure all feelings and experiences were identified inductively in relation to the interview questions. The first step in the process produced low levels of abstraction and relied on interviewees' in vivo formulations and led to two categorical 'systems'- one for expressions of feelings and one for expressions of experiences. The second step involved inductively 'discovered' expressions of positive, negative and neutral responses. The positive, negative and neutral expressions were not taken further in the analysis as the low level of quantification did not add anything to the qualitative dimension. The third step involved paraphrasing all expressions to achieve a 'condensed' and generalised higher level of abstraction.

The second procedure involved working deductively through the paraphrases with analytical concepts in a rule-guided way to derive 25 coded categories (see Mayring and von Rhoeneck, 2003, pp111-112). This is in effect second cycle coding which was intended to yield a synthesis of themes and issues available for analysis. Categories were revised using inter-coding reliability procedures by two members of the team. The next stage involved identifying 5 Main Categories (MCs) and allocating 
the coded categories to them. The coded categories were clustered analytically in relation to the research questions and framework and further developed the 5 Main Categories, which were initially theoretically derived.

\subsection{Explaining the categories}

Inductive category formation led to two separate categorical systems - one with expressions of feelings and one with expressions of experience. Definitions of both can be viewed as subjective differentiations by the research respondents - but guided by the 'deductively' shaped questions and frameworks of the researchers.

Paraphrasing helped consolidate the data and to condense it by removing phrases with the same meaning and by summarising and bundling phrases with similar content and meaning. Table 2 below shows the number of expressions of feelings and experiences and the number of paraphrases of feelings and experiences, which had been derived from the expressions.

Table 2. Number of expressions and derived paraphrases as a basis for coding and indexing

\begin{tabular}{|l|l|l|l|}
\hline \multicolumn{2}{|c|}{ Expressions } & \multicolumn{2}{c|}{ Derived paraphrases } \\
\hline Feelings & Experiences & Feelings & Experiences \\
\hline 402 & 530 & 328 & 443 \\
\hline
\end{tabular}

The total number of derived paraphrases had to be managed for category handling. The researchers determined that with the total number of 771 paraphrased statements it would be feasible to have approximately 30 paraphrases to support one category. The ultimate decision about a category was formed in reference to and on the basis of the research question. To each category formed in this way a list of paraphrases that would support it was attached. Identification numbers attached to each paraphrase allowed for continuous checks to verify that the categories would represent the meaning of the original statements in the transcripts. By further condensation, a total of 311 generalised paraphrases for feelings was arrived at and for experiences a total of 416 was achieved. The ultimate rationale for forming a category lay in the research question(s) and the conceptual framework which informed the research strategy. There was a wide range of paraphrases supporting each category numbering from 4 to 117. Quantification of this data, though interesting, is not laden with meaning in relation to the research questions. The meaningful analysis of data arises from the aggregation of the feelings and experiences expressed by students in relation to the key themes of the research project. The final total of 25 categories was supported by 311 paraphrased feelings and 416 paraphrased experiences.

Table 3. Title of Main Categories and number of coded categories per Main Category

\begin{tabular}{|c|c|}
\hline Title of Main Category & $\begin{array}{c}\text { Number of coded } \\
\text { categories }\end{array}$ \\
\hline $\begin{array}{c}\text { A Real learning-the campus } \\
\text { and its ethos }\end{array}$ & 8 \\
\hline $\begin{array}{c}\text { B A changing knowledge } \\
\text { base }\end{array}$ & 3 \\
\hline $\begin{array}{c}\text { C Forms and types of } \\
\text { learning }\end{array}$ & 4 \\
\hline $\begin{array}{c}\text { D The individual and self- } \\
\text { understanding }\end{array}$ & 5 \\
\hline $\begin{array}{c}\text { E Work and life-long } \\
\text { learning }\end{array}$ & 25 \\
\hline Total number of categories: & \\
\hline
\end{tabular}

The next stage involved decisions to group the categories with Main Category classifications, known as MCs in order to sustain an analysis of the data within the research narrative. Decisions on allocating categories to MCs were verified through co-coding and what Saldana (2012) called demonstrating necessary professional attributes by respecting the data and its integrity. The final step took place after all the data had been coded and the links between the categories and the MCs and conceptual frameworks could be seen and understood. Table 3 shows the number of categories in each Main Category. Each main and subsidiary category had eventually a list of all the paraphrases that supported it, and the number of interviewees who had indicated this feeling or experience as set out in Table 4.

\subsection{Final step}

The final step, which was the analysis and writing up of the findings, took place after all the data had been coded and the links between the categories and the MCs and conceptual frameworks could be seen and understood. The analytical findings corresponding to each Main Category are shown in the next section.

\section{Research findings}

\subsection{Real learning-the campus and its ethos}

The research subjects were students at ACU's McAuley at Banyo campus in Brisbane and were 
Table 4. Categories and codings

\begin{tabular}{|c|c|c|c|c|c|}
\hline \multirow[t]{2}{*}{ Main Categories } & \multirow{2}{*}{ Coded Categories } & \multicolumn{2}{|c|}{ Feelings } & \multicolumn{2}{|c|}{ Experiences } \\
\hline & & Paraphrases & Interviewees & Paraphrases & Interviewees \\
\hline \multirow{8}{*}{$\begin{array}{l}\text { A Real learning-the } \\
\text { campus and its ethos }\end{array}$} & A1 Catholic ethos & 19 & 14 & 6 & 5 \\
\hline & A2 Campus and buildings & 49 & 21 & 68 & 24 \\
\hline & A3 Support and inequalities & 13 & 11 & 25 & 18 \\
\hline & A4 Admissions & 3 & 3 & 5 & 2 \\
\hline & A5 Support for students & 10 & 8 & 24 & 14 \\
\hline & A6 Family support & 9 & 8 & 13 & 13 \\
\hline & A7 Community/public service & 6 & 3 & 6 & 2 \\
\hline & A8 Older students & 6 & 3 & 23 & 13 \\
\hline \multirow{3}{*}{$\begin{array}{l}\text { B A changing } \\
\text { knowledge base }\end{array}$} & B1 Subject/specialist expertise & 10 & 2 & 12 & 3 \\
\hline & B2 Core curriculum & 9 & 5 & 16 & 5 \\
\hline & B3 Social relatedness/competence & 18 & 12 & 8 & 3 \\
\hline \multirow{5}{*}{$\begin{array}{l}\text { C Forms and types of } \\
\text { learning }\end{array}$} & C1 On-line & 16 & 11 & 43 & 23 \\
\hline & C2 Social media & 0 & 0 & 8 & 8 \\
\hline & C3 Mixed modes & 10 & 9 & 33 & 16 \\
\hline & C4 Small classes and face-to-face & 10 & 9 & 22 & 14 \\
\hline & $\begin{array}{lccc}\text { C5 } & \text { Learning } & \text { outside } & \text { the } \\
\text { classroom/practical work } & & \\
\end{array}$ & 3 & 2 & 21 & 18 \\
\hline \multirow{5}{*}{$\begin{array}{l}\text { D The individual and } \\
\text { self-understanding }\end{array}$} & & & & & \\
\hline & $\begin{array}{l}\text { D1 Personal viability and personal } \\
\text { growth }\end{array}$ & 30 & 22 & 16 & 13 \\
\hline & $\begin{array}{l}\text { D2 Independent learning/self- } \\
\text { learning competence }\end{array}$ & 10 & 9 & 10 & 8 \\
\hline & $\begin{array}{lll}\text { D3 Emotional response to } \\
\text { learning }\end{array}$ & 21 & 16 & 6 & 2 \\
\hline & D4 Self-concept/self-esteem & 4 & 3 & 1 & 1 \\
\hline \multirow{6}{*}{$\begin{array}{l}\text { E Work and life-long } \\
\text { learning }\end{array}$} & & & & & \\
\hline & $\begin{array}{l}\text { E1 Development } \text { of } \\
\text { professionalism and professional } \\
\text { practice }\end{array}$ & 19 & 13 & 21 & 13 \\
\hline & E2 Expectation of future work & 30 & 17 & 31 & 17 \\
\hline & E3 Part-time work & 2 & 2 & 2 & 2 \\
\hline & E4 Volunteering & 4 & 2 & 27 & 22 \\
\hline & E5 Life-long learning & 16 & 14 & 12 & 10 \\
\hline & Totals & 311 & 208 & 416 & 246 \\
\hline
\end{tabular}

attending university where both the specifically Catholic ethos of the university and the high quality character of the campus itself were significant aspects of student life. The interviews were intended to capture the feelings the students had towards the place, the location, the buildings and the space occupied by the university. One student typically said "I like the campus because its small and I feel part of a community". The campus is physically inhabited but it is also inscribed on the sensibilities of many students. In an era of mass attendance and impersonal handling of students as consumers, the campus as a physical locus may contribute to either positive or negative feelings and experiences. In the case of ACU at Brisbane the students viewed the campus as an overwhelmingly positive asset to their lives as students. Another student said that "I love the campus, it has beautiful views, the facilities are fantastic... the new building is like a shining new light". Aesthetically many student respondents valued the beauty and tranquility of the original cloisters whilst the new Saint John Paul II building was a dazzling addition to what was for many thought of as a treasured location.

A range of campus- wide issues concerned with student support systems, admission of students, the needs of disadvantaged or minority students and the specific needs of older, return-to-learn adults were 
all mentioned by respondents in a positive light. ACU has according to one student an admissions system that was "...personal and upfront...(and) impressed me". The university appears to ensure that its systems of support are in harmony with the Catholic intellectual and ethical traditions. Particular mention must be made of the efforts to address the needs and concerns of indigenous people, which students valued highly. The research sample contained a significant number of students who have or had roles other than being a student. Most respondents thought ACU served their needs and indeed they were impressed by their younger colleagues. One said “... the attitude of young people has impressed me immensely-not only their commitment to study but the way they have accepted me in their classes and around the campus".

A small minority of students expressed concerns about parking, access to Wi-Fi in the Library and the air-conditioning/temperature in some parts of the new building. Some students were of the view that more shade and vegetation would enhance an already beautiful campus.

\subsection{A changing knowledge base}

Students at ACU Brisbane have firm expectations of what their studies will provide. This is mainly concerned with vocational and professional outcomes, ie jobs and opportunities in the labour market. The research results clearly spell out the high value students place on their lecturers' expertise, subject specialisms and professional practice. Many study programs are geared to serve future professional needs and students recognise and seek such experience and consider it highly relevant to their futures. Lecturers are highly valued and can provide excellent role models for students. One student talking about the quality of lecturers said "...they want you to succeed".

The knowledge base of study programs at ACU is not limited to specialist subject expertise. The university's core curriculum which is common to all undergraduate programs, is a pioneering development which teaches students to think critically and to be guided by social justice principles in their personal and professional lives. The research evidence pointed to the importance to students of social relationships and communication skills which are embedded in their study programs. Common learning experiences allow students to assess their own experience in relation to current social issues. Student respondents valued the community engagement and opportunity to 'live' a curriculum in action, especially where many were involved in voluntary work beyond the campus boundaries. For many students personal and professional lives were linked through their studies and voluntary work.

The research data showed the significance of localised, context specific and situated learning. This was expressed through the highly positive evaluations students gave to the subject and professional expertise of their lecturers and to the practical tasks they were called upon to achieve. Furthermore, the emphasis given to professional practice enables the student to begin to conceptualise her/him- self as a creator of knowledge rather than as a simple consumer of learning. As such, a critical and changing knowledge base can be seen to be emerging at ACU where learning is part of a social experience involving professional expertise, social well-being, personal survival and civil conviviality and engagement.

\subsection{Forms and types of learning}

There can be no doubt that contemporary learning cannot realistically live without the new technologies. 'Real learning' is now inseparable from the impact of digitalisation and the new literacies. Students in this research project were, like almost all students everywhere in the world, aware of the significance of computer-led or IT - supported learning. Multi-tasking across different IT platforms and media was common, with most programs offering significant on-line learning opportunities. Almost all the research respondents used transmedia navigation (involving desk-top computers, lap-tops, I pads, hand-held devices and smart phones) to some degree. It is impossible to conceive of a modern degree program being delivered without on-line and digital support and ACU has reached a stage where distributed cognition is now the norm.

Not all students in the research were equally enthusiastic about the benefits of new technology. Older students were less welcoming in general than younger cohorts and perceived the opportunities for learning via digital means in a less favourable light. Younger students used social media far more extensively than their older colleagues. One older student suggested that "...too much screen time is causing problems with young people (not) developing communication skills". In general all students were aware of and supported the availability of mixed-modes of learning and as one student said "... on-line working is very popular but it depends on what you are studying". There was amongst a majority of respondents a clear preference for small classes and face-to-face contact with staff. A significant proportion of students valued learning occurring outside the classroom and this was often concurrent with practical activities undertaken in 
professional and voluntary settings. Goal directed knowledge was the keystone of much practice-based learning.

\subsection{The individual and self-understanding}

A key concern for the research project involved the search for a curriculum that could be relevant to peoples' lives in an era of change, uncertainty and challenge. For many young people the future is indeed a world of uncertainty as well as being a world of opportunity. For older, return-to-learn students ACU represents a chance for personal fulfilment and achievement-perhaps denied in their past lives. However, the future may equally offer them as older adults no clear route to rewarding, professional work.

The chance to learn independently and to develop personal competences and attributes was highly valued by student respondents. Personal viability, by which is meant the capacity to sort out issues and dilemmas of a personal kind using skills and intelligence, was highly rated. These skills were recognised as contributing to students' capacities and were central to a process which recognised and rewarded 'self- learning'. This self-learning competency was in effect a part of developments in self-identity where the 'self' as learner becomes a key defining structure of personal life. It involved ACU students on campus, in the professional workplace and in local communities as active subjects engaged in learning activities which facilitated self-esteem, self-worth and a sense of membership of a wider social community. Many of the respondents expressed this through what they termed a growing feeling of confidence and recognition by their professional tutors of their competencies and capacities. One mature student said "I considered myself a reasonably good person but the University has opened up my mind and I am becoming more aware of their needs and my own"; and another said "It's the realisation that I can actually do this as a middle aged woman who's had challenging life circumstances".

Self-understanding, what Anthony Giddens refers to as 'the self as a reflexive project', also involves emotional learning and intelligence-which was evidenced in the research results. Cognitive aspects of learning such as subject expertise and conceptual strategies were influenced by the emotional bases of learning such as anxiety, indifference, enjoyment, pride, satisfaction and hope. Students expressed an individual sense of self in relation to their own real life contexts. This involved enquiring about 'self' and solving tasks as active individuals where the learner was the primary actor. This is sometimes known as action learning! The research findings highlighted the significance of self-understanding within an emerging understanding of 'real' learning and its use for students.

\subsection{Work and lifelong learning}

It is hard to over-estimate the importance to ACU students of professional employment outcomes to their studies. The interview transcripts showed the weight of concern students had for their chosen careers, and their understanding of future work as in "I'm only 23 and have had over 10 jobs already. I'm in a world with chopping and changing roles, but ACU has prepared me to go out in the world and succeed in my profession". Most of the respondents had a positive expectation of future work, though some professions such as teaching, social work and health faced an insecure financial future in Queensland at the time of the study. Older students were less optimistic than their younger counterparts for both short-term and longer term prospects.

Many students reported a desire to undertake professional development and /or lifelong learning in relation to future work. Many were already involved in volunteering and considered it a form of preparation for their careers. One student said "I am involved in Pass (Peer Assisted Study Sessions) ... and it is ...helping me to improve my confidence and public speaking". Part-time work to pay for study was common though some found it to be 'exploitative' and older students found it hard to find. Work for ACU students is significant and vocational outcomes are a source of positive motivation, encouraging a commitment to real learning.

\section{Something of what students said}

\subsection{Real learning - the campus and its ethos}

"I chose ACU because it has a strong religious vibe and there's a sense of community and compassion" (0612)

"... a Catholic ethos that supports the community (and students) that are going out with an open mind and heart into their chosen profession" (17518)

".... some of the religious aspects of ACU (have) been positive for me ... making me more mindful and caring about others" (0425)

"The smaller class sizes was my big draw card" (0312)

"I love the new building ... (it) is stunning (01517)

"I think it's (the campus) beautiful and I do appreciate the development and the time and money that the campus is spending to improve our 
university. I like to study outside because I think the fresh air helps a lot and relaxes me" (23417)

"I love the campus and the new building even though the air con on the third floor in the lobby area does not work and it gets quite hot" (18417)

"I feel this University needs a bit more shade" (06417)

"Indigenous and Torres Strait Islander friends have come to ACU (and) they have been provided with opportunities they may not have received elsewhere" (01116)

"ACU definitely has that multi-cultural vibe" (2415)

"Well I'm an ACU ambassador now for the unit down there (Weemala) and I go around on some days to schools promoting our uni" (0839)

"... there is a need for more mental health support" (14310)

"My favourite spot in the university is in the library" (21311)

"Wi-Fi is slow... couldn't (always) get access in the Library" (1513)

"My family are very supportive and I don't think I would be able to do this study without their support" (1628)

\subsection{A changing knowledge base}

"(My) mentor or supervisor has had the most positive impact for me" (01412)

"My lecturers see us all as individuals and are prepared to adapt to our different ways" (03313)

"I think the lecturers are great" (07313)

"My lecturers are passionate about (their) subjects" (0913)

"Studying Sociology relates to everything and to life in general" (13515)

"Lectures help you understand life" (1425)

"Being able to have a professional relationship with my lecturers has helped me to develop and grow" (1625)

"I like practical and ... try out what I have learnt in class and find out what my best approach is" (17415)

\subsection{Forms and types of learning}

“... if you can't make a lecture they upload them online so you don't miss out" (1613)

"Personally I like to attend lectures (and) prefer faceto-face) (0213)

“... our own private Facebook group (has helped) to clarify questions and share information) (0513)

“... working online (the) majority of us don't like it but being older I don't find it particularly helpful in my learning. Younger students will find it more helpful ...but I like to talk face-to-face with a lecturer and receive feedback" (1814)
"I think that completely online undergraduate studies is a recipe for disaster - because there (would be) very little possibility of human engagement" (2224) "On-line working helps me manage my studies as I am a lone parent and so it gave me an extra hour a day instead of travelling in" (1813)

"Having on-line and meeting with others and lecturers is a good mix" (2014)

\subsection{The individual and self-understanding}

"Uni has helped me develop empathy and awareness of others" (0139)

"I am so joyful with everything I've learnt it's just a wonderful feeling" (10312)

"It (Uni) is helping me see the bigger picture" (1239) "I have been able to use my intelligence and have found I can learn and this did not happen at school" (13413)

"I've learnt how to talk to big groups of people and how to present (myself) properly" (1639)

"... learning how to write an essay was an incredible hurdle for me. My self-confidence is better” (1839)

\subsection{Work and life-long learning}

“Our Professional Practice Educators are also a great source of information) (03415)

"Ten years ago ...you could have walked straight into a job... it is harder these days" (01310)

"...uni teaches you how to handle yourself ... I now know how to make myself come across as someone they want to hire" (09310)

"I need to know that the bills are going to be paid and the kids looked after" (13310)

"Don't always get enough meetings with people from outside eg hospital staff" (15310)

"I feel very prepared to go out into the world with an ACU degree behind me" (09414)

Code for student quotes: the first two numbers in brackets after each quote identifies the coded transcript number, the third number refers to the page number and the final number/numbers refer to the question number.

\section{Conclusions}

This research project has highlighted the fact that ACU Brisbane has embedded applied and innovative curricula across many of its programs, ensuring its students are work ready upon graduation. Students reported that ACU Brisbane's curriculum at its best is real, relevant, dynamic and alive and makes a positive difference to their lives particularly through their emerging world of work. In this way ACU 
establishes a strong partnership with its student body; a social contract, that encourages their role as creators of practitioner knowledge. Respondents cited good examples of this such as the Clinical Schools established across Queensland that immerse Health students in experiential learning as part of their program. These facilities represent University spaces embedded in working hospitals, recognising the fact that real and relevant learning may not necessarily happen just at the University campus, nor in the world of work - rather, in a combination of the two.

Respondents noted the significant success the campus had achieved in creating a learning environment that encouraged the development of the whole person - the mind, the body and the spirit. Many commented positively on the stunning new building that completes the University Courtyard. Named in honour of Saint John Paul 1l, the majority of the building is dedicated to teaching and learning spaces, both formal and informal, and serves as an iconic example of ACU Brisbane's commitment to creating innovative spaces to facilitate cognitive and critical thinking.

The new building undoubtedly creates a unique space for students to think and reflect critically through the innovative use of formal and informal learning spaces. It also acts as a focal point for an emergent paradigm that seeks to combine the University's role as a centre of recurrent learning and teaching, its role within a regional community and the variable pacing of study and flexibility in course provision it offers to its students. The key to these developments is access, by which is meant the widening of participation, the modularisation of courses enabling greater student choice and the onset of new technologically-based learning systems such as that offered by the internet. All of this has occurred in the context of a continuing expansion of professional and vocational education on campus and within a wide variety of workplaces. In this way ACU Brisbane has sought to facilitate understanding through immersion. Both the rise in attainments and the expectations of mature adult students have been matched by a growth in the number of students requiring qualifications and/or formal recognition of their learning achievements. Many such students are almost exclusively off-campus in terms of their physical or geographical location, studying in local neighbourhood centres and have, up to very recently, been viewed as a marginal cohort of university students.

The value of the reflexive, autonomous learner is paramount at ACU Brisbane whose staff conceives of learners creating knowledge in a learning society which demolishes the barriers to learning. ACU
Brisbane has established major satellite Centres off campus near its future student market and closer to its strategic partners and stakeholders. The University campus can no longer be the epicentre of learning it once was. Formal institutions of learning now compete with informal and 'edutainment' learning via fax, journals, TV, radio, video, text messaging, satellite broadcasting and a panoply of multi-media gadgets and internet-based data, and entertainment.

All of this development throws into relief the historical privileging of teaching rather than learning. Under the new learning opportunities, teaching has had to become more pro-active and learner centred in order to retain its impact and potency. Many teachers at ACU Brisbane have therefore become creators of support systems for autonomous and reflexive learners. How individuals learn and transmit to each other what they have learned becomes a vital element of the ACU Brisbane learning community. Personal autonomy, choice and the application of reasoned and critical insightful questioning does not arrive simply on time, as does the daily rising of the sun at the appointed hour. It is always part of a struggle to create and transmit understanding and meaning in social life. It seems self-evident that the current freedoms and autonomy on offer demand committed learners who are themselves prepared to sacrifice some of their autonomy and choice, for the rewards of longer term achievement. As ACU Brisbane moves towards the reality of the development of new curricula we can see the outlines of a learning society emerging, and we may need to admit to ourselves that we are all apprentices in the learning game. The chances of achieving mastery, however, are greater for most people than they have ever been.

This report can be seen as the start of an ongoing study to inform and critically analyse developments in universities world-wide which have impacted on students' choices of ways of learning and of study subjects. Globalisation, mass higher education developments and digitalisation have meant greater emphasis on student choices and expectations, which now demand more critical appraisal and hence research. The benefits and impact of the research findings of this project give credence to the student voice and help inform the debate about change in the reform of the higher education curriculum. Higher Education Institutions can no longer afford to simply be reactive as change advances. There is a challenge to innovate and embrace modernity in curricula and research as well as buildings, which impacts directly on students and shapes their experience and expectations. University leaders, more than ever before, need to look beyond the geographical borders 
of their campus which can no longer be seen as the Epi-centre of learning it once was. Fast moving and far reaching reforms continue to sweep across the Australian university sector bringing about change in the learning opportunities within higher education and in the wider context of the workplace.

The project's findings suggest that the emphasis given to professional knowledge and practice can be underpinned by recognition of a number of factors which impact on current learning. These include the importance of personal viability and selfunderstanding where both survival and success mean individuals must promote their skills and capacities, establish a balanced life where personal needs and social awareness are reconciled, and accept responsibility for learning and self-development in the world of digital communication. The new learning, it is hoped, will stress the equality of the instrumentalist world of professional practice alongside the need for belonging, connectedness, for self-esteem and personal autonomy. In such a way personal fulfilment in and through learning can be commensurate with progressive social and community life.

Each successive generation has its own character and distinctiveness, and forms of knowledge and learning evolve to meet new needs and demands. In the practice-based, enquiry driven learning programs on offer at ACU Brisbane, the outlines of an emerging 'real' and values based curriculum can be seen. This focus on real learning and character development, driven by the student voice and embraced by our campus has created a momentum capable of scaling the steepest precipice.

\section{Conclusion}

All successful research raises more questions and some of these, which surfaced in the research project, are outlined below:

1. Is there a 'contract culture' in HE, which is becoming more specific in terms of student expectations?

2. Do the majority of students have acknowledged roles other than as learners?

3. Do we have an 'adult higher education' where mature students predominate and therefore adult relationships with the university are expected?

4. Do universities regard the student voice and experience as an authentic and valid field of enquiry? 5. Are there in effect different student markets and does the prevailing culture allow these to be explicitly recognised?

6. Is there still a 'normative' student in an increasingly diverse community and world?
7. Do HEIs recognise learning in the context of the whole person and the role of the 'self'?

8. Are private and personal roles and personal viability gaining traction and recognition?

9. Is the huge impact of digital technology benign or not and can it be managed or should it be restricted?

10. Whilst adjustments have been made to accommodate the diversity of student groups, and some teaching and learning strategies have been amended to deal with larger student numbers, have there been significant changes to the HE curriculum which reflect the challenge of change?

11. It may be that universities' perceptions about their students are being challenged as never before. This research has shown that even a high degree of student satisfaction can contain uncertainties and that the culture that underlies an institution must constantly seek renewal and relevance. If there is to be 'real learning in a changing university' then thought and debate about the student voice must be renewed. It is hoped that this ACU Brisbane project has made a contribution to this objective.

\section{References}

[1] Barber, M., Donnelly, K. and Rizvi, S., (2013). "An avalanche is coming: higher education and the revolution ahead". A report London: IPPR.

[2] Blaikie, N., (2007). "Approaches to Social Enquiry" 2nd ed. Cambridge: Polity Press.

[3] Castells, M., (1996). "The Rise of the Network Society" Oxford: Blackwell.

[4] Castells, M., (1997). "The Power of Identity-Vol 2 The Information Age-Economy, Society and Culture" Oxford: Blackwell.

[5] Davies, D., (1998). "Towards a learning society". Ch 1 in Teare et al, (1998) London: Cassell.

[6] Finegold, D. et al., (1992). "Higher EducationExpansion and Reform” London: IPPR.

[7] Flick, U., (2009). "Introduction to Qualitative Research" London: Sage Publ.

[8] Gibbs, R.G., (2007). "Analysing qualitative data" London: Sage Publ.

[9] Habermas, J., (1983 and 1987). "Theory of Communicative Action” Boston: Beacon Press.

[10] Higgins, T., (1994). "Application Procedures to Higher Education” Ch 2 in Haselgrove (Ed) (1994).

[11] Giddens, A., (1991). "Modernity and Self-Identity: Self and Society in the Late Modern Age" Cambridge UK: Polity Press. 
[12] Haselgrove, S., (ed) (1994). "The Student Experience" Buckingham: The Society for Research into Higher Education and Open University Press.

[13] Kolb, D., (1984). "Experiential Learning: Experience as the source of learning and development" New Jersey: Prentice Hall

[14] Mayring, P., (2000). "Qualitative Content Analysis" Forum: Qualitative Social Research Vol.2 (1).

[15] Mayring, P., (2007). "On Generalisation in Qualitatively Oriented Research" Forum: Qualitative Social Research Vol. 8 (3).

[16] Mayring, P. and Glaser-Ziduka, M., (2003). 'A Qualitative oriented approach to learning emotions at school' in Mayring and Rhoneck (eds) (2003) "Learning Emotions" Frankfurt am Main: Peter Lang.

[17] Mayring, P. and von Rhoeneck, C., (eds), (2003). "Learning Emotions" Frankfurt am Main: Peter Lang.

[18] Mezirow, J., (1981). 'A critical theory of adult learning and education', Adult Education, 32(1) $1981 \mathrm{pp}$. 3-24.

[19] Mezirow, J., (1990). 'How Critical Reflection Triggers Transformative Learning' in "Fostering Critical Relection in Adulthood" Oxford: Jossey Bass.

[20] Otter, S., (1992). "Learning Outcomes in Higher Education" London:UDACE/HMSO.

[21] Robbins Report, (1963). "Higher Education: Report of the Committee" Cmnd: London.

[22] Schon, D. A., (1983). "The Reflective Practitioner" San Francisco: Jossey Bass.

[23] Schor, I., (1980). "Critical Teaching and Everyday Life" Boston: South End Press.

[24] Seidman, S., (1998). "Contested Knowledge: Social Theory in the Postmodern Era" Oxford: Blackwell.

[25] Teare, R., Davies, D.W., and Sandelands, E. (1998) "The Virtual University: An Action Paradigm and Process for Workplace Learning” London: Cassell.

[26] Teare, R., (2013). 'Personal Viability - The Journey to Self-Reliance and Financial Independence' in ZuberSkerritt, O. and Teare, R. (2013) "Lifelong Action Learning for Community Development" Rotterdam: Sense Publications.

[27] Saldana, J., (2013). "The Coding Manual for Qualitative Researchers" 2nd ED. London: Sage Publ.

[28] Walsh, D., (2004). 'Doing Ethnography' in C. Seale (Ed) "Researching Society and Culture" 2nd ed. (2004) London: Sage Publ.
[29] Welton, M., (2005). "Designing the Just Learning Society: a critical enquiry" Leicester: NIACE.

[30] Woods, P., (2006). "Successful writing for qualitative researchers" 2nd ed. London: Routledge.

\section{Annexes}

\section{Annex 1}

Real knowledge: towards a new university curriculum? - A summary paper of themes and issues

This summary paper seeks to record issues about the quality and meaning of education; specifically about how university study might respond to a changing and de-stabilising world which simultaneously offers great opportunities and growth to mass higher education but excludes masses (billions) from the benefits of learning. The summary records the conceptual mapping which preceded and informed the development of the ACU research project.

The rapid pace of social and economic change, the apparent quickening of mass migration across large parts of the globe, the de-industrialisation of many traditional manufacturing heartlands and the "hollowing out" of many traditional economies and communities have meant the growth of more challenges to the neoliberal consensus and dominance of so many societies. Civil society has had to respond with creativity and opposition to the threats it has perceived. Universities are a critical part of society's response and what they produce as knowledge and qualifications has a role to play in shaping the future of many. The directions we take to overcome the issues are central to the role of universities and they can offer extended possibilities for research, knowledge production and education to meet the challenges of change.

A changing social and economic reality has been accompanied by a rapidly changing knowledge base. The knowledge economy has expanded not only in relation to employment opportunities but also in terms of its structure and its reach. New fields of knowledge and expertise are created continuously and expand beyond the old boundaries. The knowledge and information-based service industries have grown beyond all recognition within a decade and continue to proliferate. The traditional role of higher education could be said to be under scrutiny and its future brought very much into question. The simultaneous creation of local and global knowledge and its 'instantaneous' communication and sharing is also creating a commonly shared culture of sorts, regardless of the content being transmitted. This may 
yield potential for social and communitarian aspirations as some have argued (Zuber-Skerritt and Teare, 2013) if the focus can be learning which is learner-centered, self-directed and action - oriented towards improving the chances and opportunities of those most in need of learning- these are the poor and dispossessed, who exist on a truly global scale. However, the issues we are raising are not limited to only the world's poorest people. They affect us all.

This paper argues that it will require universities to reach out to new learners and new publics within civil society and for a new curriculum to emerge which is able to deliver the new learning. This is a narrative of optimism which seeks to recognise the experiences and aspirations of many who are excluded precisely because their "schooling" does not recognise their own situation and therefore does not equip them with means to overcome it.

\section{A new curriculum for universities?}

The starting point in this paper is the experience of life itself, including its essential engagement with work as a primary object of education, and therefore as a key source of learning.

This paper aims to explore and understand something of the nature of knowledge that can be gained beyond the lecture room. It focuses on issues to do with learning and knowledge in workplaces and life experience. It is less concerned with the psychological aspects of learning or the concept of culture in the workplace that has been the focus of much of the academic study of management development.

The central theme of this part of the paper is concerned with how universities can draw upon the experience of practitioners and how knowledge and learning within workplaces and communities can be recognised. Crucial to this are the questions of what are the kinds of knowledge that derive from learning in these situations and how can the modern university respond and win its place in the new order?

If we want to locate the new learning in the context of social enquiry and advocate its capacity to generate critical and transformative knowledge, we need to identify and operationalise its distinctive principles, its body of theory and its practices. This summary paper seeks to identify some relevant concepts which might underpin a new approach to university-based knowledge.

\section{Digitalisation, the tech utopia and future learning}

Gone are the days of extended individual tutorials with professors who had time, space and the inclination to induct the best and brightest into their arcane world of study and research at a leisurely pace and the internet has changed our lives forever in that we can access information and share things in ways simply not possible to any previous generation. For both good and ill we can say the internet has transformed the way people are able to communicate and exchange knowledge and information.

One of the contexts we would suggest should shape our response might be how such technology does or does not increase our personal autonomy and enhance our freedom to be what we might be.

There is another level of disturbing actuality about the internet which has resonances for educators. Realities for individuals are being reshaped and it can be argued that there is taking place a forced marriage between technology and narcissism.

The internet based social media are recognisably already in existence, manufacturing social needs through the manipulation (albeit freely with consent) of individual desires and needs. The threat lies in the psychological anxieties created by the undermining of individual autonomy and independence necessitated by the technological and psychological dependence on hardware and software which is more and more embedded in our daily lives. What needs to be explored therefore, is not just the changing interface between us and the outside world but a more fundamental shift in ourselves. What is at stake is our concept of an essential self, the idea of subjectivity and a unique way of experiencing the world and sharing that with others.

\section{The curriculum as critical social enquiry?}

Our understanding of what becomes accepted as 'proper' knowledge is rooted in academic subject knowledge and professional practice. However, our argument here is that it must also be rooted in the social processes of enquiry. These processes are themselves part of communal life and culture and must reflect what is important in the culture. These may at the same time be intensely personal and 'biographical'. This is the point of condensation where the personal becomes professional and where the intensely individual character of lived experience is seen as part of the broader social network. Professional learning as we have defined it here is therefore significant because it can produce a social result. It builds the capacity to offer a critique of existing practice and systems of activity or "action", regardless of the specific subject matter of any such system. It offers the potential of dealing independently with any particular context and with 
all such contexts. In this sense it has universal appeal and significance.

These are important questions and claims and lead us to ask ourselves - what are the distinctive principles and types of learning and knowing which could inform a critical curriculum which would be "real" knowledge, as part of the future for universities? The following 6 elements might be considered to be part of the answer.

\section{The individual as a creator of practitioner knowledge.}

It is in the personal and biographical encounters and in the intrinsically individualised experience which can be brought into conscious engagement with the task of social enquiry and social action that we find new knowledge which is capable of challenging and transforming actual, empirical "in the world" situations. This new knowledge it can be argued, is intensely linked to the practical involvement of the individual and it is suggested that it is transformative (rather than simply informative) of both the external context and object of research and of the individual her/himself (Barber et al 2013)

The development of professional and personal capacities which enable the individual to reflect and to use reflexive action are part of the acquisition of relevant skills. They are rooted in personal and professional experience and are intrinsic to what Mezirow (1981 and 1990) called "perspective transformation".

\section{Cognitive and critical thinking: the social dimension}

The workplace is not the totality of existence and neither is it hermetically sealed off from the rest of life. The everyday encounters of what Jurgen Habermas (1983 and 1987) called the lifeworld are critically part of the cognitive maps of understanding which people use to make sense of their lives (Welton, 2005).

Habermas saw modernity as driven towards accepting work-focussed, instrumental and rational efficiency as the dominant form of social logic. Increasingly this form of rationality was able to displace the lifeworld which comprised the symbolic aspects of life which were needed for successful social integration and social evolution. Older belief systems, values, social norms and ways of being were being undermined by the juggernaut of technical, rational progress. The links between the individual and the family, the culture and traditions in early and pre-modern society were being lost as modernism and the global market economy evolved.

Cognitively, the professionally relevant university degrees stress the equality of the instrumentalist world of professional practice alongside and equal with the needs for connectedness, for belonging, for self-esteem and for personal autonomy and self-realisation that is often bound to the individual's lifeworld. Habermas insists that $\mathrm{t}$ recognition should be given to the reflexive capacity of the individual who is embedded in a web of relationships and social meanings.

\section{Work and the knowledge economy}

However we choose to conceptualise work in the modern era, there can be no denying its centrality to how we understand ourselves and our surroundings. It remains for most of us the means through which we achieve a sustainable life and it is a key purpose of life itself. Through work we make ourselves and the world around us and therefore work is anthropologically central to what we are and what we might be.

Work itself is increasingly organised and distributed via the new communication technologies and this impacts on economic and social life in fundamental ways. According to Manuel Castells (1996, 1997) the economy has become globalised and is maintained by endlessly complex and massively expanded financial flows. The industrial corporation has become a network, as opposed to the taylorist hierarchy of control and production located in an institution or even a place, which was the case in previous eras.

In this context we can surely identify the need for a more educated and autonomous working population? The prospects are grim without such a vision. Notable commentators (Robbins, 1963; Otter,1992; Finegold,1992; Castells,1997; Barber et.al., 2013) have identified the economic arguments for global change and the need for new types of learning over recent decades.

\section{Understanding through immersion}

The curriculum reforms indicated in this paper suggest an approach which privileges the viewpoint of the learner as a knowing subject in the institutional context in which she/he works and studies. The approach stresses that mutual knowledge can be generated in the encounter between a practitioner learner and the object of knowledge or study. This object of course may be, and frequently is, a thinking subject within a social and civic activity. In other words individuals as learners are thinking beings who seek to change their circumstances and their selves as they solve real life problems facing them (Schon,1983; Teare, 2013).

Immersion in the subcultures of work and social life by such learners is seen as a key to the generation of what Giddens has called mutual knowledge. By this is meant the understandings that 
are won in the world of work and elsewhere which gives access to an adequate understanding of what lies behind behaviour and perceptions

The chosen emphasis is on the processes of observation, practical immersion in tasks and problems to be resolved, reflection on meanings and processes undertaken by participants and on continuing analysis of results which are perceived as tenuous and conditional.

\section{Operationalising knowledge}

The emergence of new and innovative forms of study (Schor, 1980; Teare and Zuber-Skerritt, 2013) has signalled an overall shift in the focus of learning opportunities. Such participation is matched by a rise in attainments and the legitimate expectations of such students for the highest levels of qualifications and this has implications for university studies world-wide.

The "new curriculum" suggests a re-shaping of the conventional structure and content of university degrees and illustrates the emergence of a new paradigm of learning whose focus is firmly on constructing knowledge in contexts where it has an impact on the studied object. Responsibility for one's own self and for others frequently plays a significant part in conceptualising such projects and the relationship of individual purposes and social concerns and values are problematised.

The elements comprising this operationalisation of knowledge include the use of work and productive life as a progressive principle for the making and progressive reshaping of the HE curriculum.

\section{Reflexive practice}

It is Anthony Giddens (1991), who provides us with a potential framework for conceptualising the role of the self as a reflexive agent in the process of knowledge production. People are engaged in producing and reproducing their own social world and have the capacity to make choices and to act differently. According to this view they have the capacity to reflexively monitor their own actions and to rationalise these actions. They are able to engage with their own motives and with their unconscious motives.

Giddens has used the idea of the self as a reflexive project itself in modern life, where critical engagement with the meaning and actions of one's own life is the focus of attention. The wider social and community realities and the individual actions we can observe are, according to Giddens, simply different aspects of all social practices. The social system or structure is not a reality apart from the individual but it exists in the minds and experiences of individuals as practical knowledge. The key concept here is of social practice, where people using reflexive techniques can generate social scientific knowledge and can incorporate it into their behaviour and thereby change the conditions of its validity. ...." a processual theoretical view of social life" is envisaged (Seidman, 1998:149).

\section{Real learning: towards a synthesis of elements}

1. The Individual as a creator of practitioner knowledge

- Personal/biographical change and growth which has empirical and theoretical aspects e.g.:

$\circ$ personal job change

- growth of 'constructivist' viewpoint

○ application of theory to reality

$\circ$ the challenge of real world situations

- not first informative but transformative

2. Cognitive and critical thinking

- de-monopolise knowledge

- critique of pre-formulated knowledge learning not just knowledge acquisition

- inter-disciplinarity

- collaborative learning/shared learning

- modelling learning process and the 4 levels of thinking

- management problem solving

- cognitive gains (dynamic curriculum)

3. Transferability of skill and experience

- reflection on professional practice

- authoritative involvement in professional life

- self-knowledge, evaluation

- resolution of problems - with degrees of unpredictability

- recognition of a range of situations

4. 4. Understanding through immersion

- creative translation of meanings between contexts

- synthesis of different elements

- contradictions (recognise if not resolve)

- bring about thinking change

- symbolic analysts (Giddens)

5. Operationalising knowledge

- use innovative study and research

- responsibility for self and others - individual purposes and social value

- face dilemmas (ethics) and find solutions

- action bias and active agent 
6. Reflexive practice and the 'self' as a reflexive project

- autonomy, individuality and equality

- address issues of knowledge, culture and power

- show how culture defines what counts as knowledge

- development of self-learning competency

Annex 2

Interview questions

ACU Brisbane Research Project: Real learning in the changing university

1. I wonder whether you can tell me what you are doing at ACU. What course are you on and which year?

2. What makes ACU special for you and why did you choose it?

3. How much of your course is delivered using on-line learning or other digital technologies and how important or useful are they? What other kind of media do you use personally?

4. Do you think students in the future will always need to attend the campus in person in order to gain a qualification?

5. What do you think you are learning at ACU or have learnt which will help you deal with your life as well as your work and career?

6. Are you involved in any volunteer activities in the community through the University and/or through the Church?

7. Do you expect during the first 10 years of your working life to continue learning and gaining qualifications after you have achieved your degree?

8. Do you think you will be successful in your career and in your life? Will your family help you in anyway?

9. How has the University helped you to develop as a person and to develop your abilities and talents?

10. Work in the future may be short-lived and unstable, how equipped do you think you are to deal with this type of environment?

11. How do you learn best? Do you learn through acquiring knowledge of a subject? Do you learn through interdisciplinary studies? Do you learn through action learning in a group or community? Do you

learn through self-reflection?

12. What makes you feel joyful about your studies and helps you to achieve?

13. What do you think is the quality or thing which has the most decisive impact on a positive outcome for you here at ACU?

14. Do you think you are employable? Have you developed a career focus through your studies?

15. How much learning about your subject do you get outside of the classroom and how?

16. In your experience does the University serve the needs of minorities and groups previously excluded from higher education and does it work for social justice?

17. How does the ACU campus and its new buildings at Brisbane impact on your studies?

18. Universities often state their belief in learning for a better society. What does this mean for you and your studies here at ACU?

\section{Annex 3}

\section{Initial framing questions for the research interviews}

1. What are the progressive possibilities for universities in 2014-2020?

2. How can we understand how values can drive behaviour?

3. Is it only utilitarian arguments or the language of markets that hold sway?

4. How does the university give service to the community?

5. How is learning responding to the possibilities for change?

6. How are ACU developments rooted in student needs and perspectives?

7. Is the globalised future demand-led and consumer oriented?

8. Is the 'hollowing out' of traditional economies impacting on ACU students?

9. What will mass higher education mean for future campus-based learners and for those off-campus?

10. Is the traditional place and function of the university under threat?

11. Is the civic role of the university being developed or lost? 
12. How does ACU view the impact of its new buildings on its students and on its sense of itself as an institution?

13. Are modern students more or less autonomous and self-reliant?

14. How does the modern university develop its offer to the disadvantaged communities that need higher education?

15. Must hierarchies of excellence and quality become effectively methods and means of re-constructing privilege?

16. How are decision makers to reconcile the "freedom" to attract greater student numbers but often within a declining resource base?

17. How does the increasing digitalisation agenda impact on students' learning and identities?

18. Is there a real and relevant curriculum for a modern university which is different from that of the past?

\section{Annex 4 \\ Index of documents supporting the research project}

1. Doc.1. (November 2014) A Summary paper "Real Knowledge: towards a new university curriculum?" LICE Conference, London, UK

2. Doc.2. (January 2015) Extended abstract 'Old wine in new wine-skins?' - towards a new university curriculum

3. Doc.3. (03.01.2015) Information Sheet for ACU Staff

4. Doc.4. (03.01.2015) Semi-structured interview questions, draft

5. Doc. 5. (03.01.2015) On-line questionnaire, draft

6. Doc.6. (04.01.2015) Information sheet for students

7. Doc.7. (04.01.2015) Project arrangements students and domestics

8. Doc.8. (06.01.2015) A note on research methods

9. Doc. 8 (28.07.2015) A note on the Mayring method of coding 